\title{
TONY GARNIER E A CIDADE INDUSTRIAL
}

Bruna de Andrade Ferreira, Christian Pires, Jacqueline Saab, Larissa Rodrigues, Letícia Bortolo, Rafaella Prado, Yasmin Perosso, Korina Costa

Universidade do Oeste Paulista - UNOESTE. Curso de Arquitetura e Urbanismo, Presidente Prudente - SP. E-mail: yasmin perosso@hotmail.comm

\section{RESUMO}

Com a Revolução Industrial em grandes cidades da Europa Ocidental no século XIX surgiram problemas devido ao crescimento populacional sem planejamento urbano adequado, como também a desenfreada especulação imobiliária, um sem fim de fábricas poluentes, péssimas condições sanitárias e habitacionais. Por meio de propostas surge então o modelo de civilização ideal "Utopista", uma cidade imaginária, fantástica. A proposta de Tony Garnier para a cidade Industrial era separar distintos lugares em zoneamento. Em Lyon, na França, Garnier fez diversas obras, como o Hospital de Grange - Blanche, o Estádio Municipal de Gerland e a Halle que hoje é um Monumento Histórico.

Palavras-chave: Revolução Industrial; Planejamento Urbano; Cidade Industrial; Tony Garnier; Utopista.

\section{TONY GARNIER AND THE INDUSTRIAL CITY}

\begin{abstract}
In the nineteenth century, during the Industrial Revolution in large cities of Western Europe there were problems due to population growth without adequate urban planning, as well as the rampant property speculation, endless polluting factories and inadequate sanitary housing conditions. Through proposals grown up an ideal model of civilization "Utopian", an imaginary, fantastic city. The proposal from Tony Garnier for Industrial city was separating distinct places in zoning. In Lyon, France, Garnier made several constructions, such as the Grange Hospital Blanche, the Municipal Stadium from Gerland and Halle, which is now a Historical Monument.
\end{abstract}

Keywords: Industrial Revolution; Urban Planning; Industrial City; Tony Garnier; Utopian. 


\section{INTRODUÇÃO}

De acordo com (BENEVOLO, 1981):

A história da urbanística moderna é, numa primeira fase, uma história de simples fatos: as mudanças produzidas gradualmente pela revolução industrial nas cidades e nos campos só mais tarde surgem claramente e são percebidas como problemas, quando as quantidades em jogo se tornam suficientemente grandes. A primeira mudança decisiva é o aumento de população, devido à diminuição da taxa de mortalidade que, pela primeira vez, se afasta decididamente da de natalidade. À medida que aumenta o número dos habitantes, muda a sua distribuição no território como efeito das transformações econômicas.

Por meio de propostas como as das Industrial Villages e dos Phalanstères, de autoria, respectivamente dos utopistas Robert Owens e Charles Fourier construíram cidades modelo conjunto a suas fábricas.

A simples necessidade de certa ordenação do suprimento de água e da rede de esgotos transformou o planejamento urbano numa questão de ordem técnica. Outra forma de planejamento urbano foi o drástico embelezamento de Paris, recortando os super povoados quarteirões da cidade com largos boulevards canteados de novas fachadas.

Essa demonstração de força suscitou a admiração dos demais países da Europa e foi repetida em escala menor em muitas cidades. Mas os novos assentamentos que surgiam no entorno das cidades existentes, graças ao direito de propriedade privada, foram difíceis de manter sob controle.

A proposta de Tony Garnier para a cidade Industrial era, sobretudo de uma cidade socialista sem muros ou propriedade privada, onde todas as áreas não construídas eram parques públicos.

O plano linear de Garnier separava as zonas industriais, da administração e das residências. Além dessas características no planejamento urbano, havia também o uso do novo material, o concreto armado, que era a potencialidade estética do século XX.

Tony Garnier realiza sua cidade ideal em Lyon, localizada na França onde também constrói muitas outras obras como uma arena multiuso, originalmente como um matadouro, o edifício foi renovado em 1987 e aberto como uma sala de concertos em 1988. 


\section{METODOLOGIA}

A pesquisa foi desenvolvida com base nos livros que tratam de assuntos da época em estudo e suas características arquitetônicas. Além de pesquisas na internet, foi somado o conhecimento adquirido no ambiente acadêmico.

Cuja investigação se fundamentou na abordagem qualitativa de pesquisa, utilizando-se da pesquisa de levantamento bibliográfico e da pesquisa documental, que segundo Teixeira (2000, p. 137), busca a correlação entre a teoria e os dados, entre o contexto e a ação, a partir da compreensão dos fenômenos por meio de sua descrição e interpretação. Para o trabalho com o estudo do tipo de levantamento bibliográfico ocorreu inicialmente um levantamento das principais produções no contexto nacional de estudos, considerando a peculiaridade do objeto de estudo.

Desse modo, percebeu-se que a pesquisa qualitativa vale-se do método indutivo, segundo o qual parte da observação, da análise dos fatos particulares, dos registros para compor um quadro compreensivo para então constituir a generalização universal, ou seja, a teoria. O processo de indução vale-se do princípio do empirismo, no qual o conhecer é dar significado à realidade (KÖCHE, 1997, p. 62).

\section{O SURGIMENTO DO URBANISMO E AS PROPOSTAS DE SOLUÇÃO PARA AS CIDADES.}

Segundo (BENEVOLO, 1923), o intervalo de tempo considerado na História da arquitetura moderna, do último terço do século XVIII ao final do século XX, a paisagem construída sofreu quatro transformações sucessivas, cujos efeitos se encontram combinados na paisagem de hoje.

Com o fim dos assentamentos tradicionais, surge um primeiro modelo de urbanização "moderno", concebido por volta da metade do século XIX com as características de partilha de solo urbano e territorial entre as administrações públicas e privadas; divisão de trabalho nos gêneros técnico e artístico; uma definição do repertorio formal do qual extrair essas variantes que inclui todos os modelos oferecidos pelas muitas épocas do passado e por todos os países.

Benévolo diz ainda que, com o fracasso do primeiro modelo foi criado um segundo, colhido pelo movimento moderno no primeiro pós-guerra, com as características de uma nova abordagem da projetação do ambiente construído, onde é rejeitada a distinção entre as duas abordagens tradicionais, a técnica e a artística; um campo novo e mais vasto de escolhas não dependentes dos modelos do passado e livre de sujeição às regras da perspectiva; nova divisão de tarefas entre a administração pública e outros operadores. 
Contudo, tais modelos não conseguem satisfazer as necessidades dos cidadãos mais pobres que abandonam os antigos assentamentos por causa da explosão demográfica e da migração do campo para as cidades.

Com a Revolução Industrial houve um rápido e significativo desenvolvimento, que se deu em relação a cidades inglesas, rapidamente atingiu, também, a França e a Alemanha.

Surgiram problemas devido a essa migração como o crescimento sem planejamento, a desenfreada especulação imobiliária e um sem fim de fábricas poluentes. Acarretando péssimas condições sanitárias e habitacionais e a liberdade de abusar do direito de explorar a miséria humana.

Os privilegiados buscando guarida nos melhores enclaves do centro urbano ou em áreas reservadas às suas mansões na periferia. Áreas da preferência dos visitantes da cidade, sem contato com a miséria da periferia e do entorno, situação ainda hoje reconhecida em nossas próprias cidades.

Como solução surge então o modelo de civilização ideal "Utopista", segundo o dicionário Michaelis a palavra utopia significa fantasia, logo o modelo nada mais é que uma cidade imaginária, fantástica.

Com relação ao crescimento das cidades como fenômeno social, os planejadores da época não apresentaram nada de novo, a exceção foi Ebenezer Howard com sua ideia de cidade-jardim, apresentada em 1897. Queria simplesmente estancar o crescimento das cidades e dirigi-lo para assentamentos industriais autônomos e reunir as vantagens de se morar na cidade com as vantagens de se morar no campo.

\section{URBANISMO DE TONY GARNIER}

A cidade de Lyon, a terceira da França em tamanho, sofria as consequências do crescimento de uma cidade grande. Um centro mundial da indústria da seda, mas também com grandes fábricas de maquinaria e de produtos químicos.

Passou por consideráveis transformações na segunda metade do século XIX. Já nos anos 1860 foi objeto de trabalhos de saneamento urbano tendo Paris como modelo. Em 1880 realizaram-se vários projetos de renovação urbana com um enfoque nitidamente sanitarista, e em 1900 foram implantadas instituições de educação e outros serviços dignos de uma metrópole regional.

Esse contexto teve importância para o jovem arquiteto Tony Garnier, que nasceu em 1869 e cresceu num dos melhores bairros operários de Lyon. Estudou arquitetura na Academia de 
Belas-Artes daquela cidade entre 1886 e 1889. Em 1889, foi contemplado pela Academia de Lyon com uma bolsa para formação continuada em Paris. Ali chegou, portanto no ano da grande exposição internacional - a exposição da qual a maioria se lembra por causa da torre Eiffel.

Segundo o professor Frank Svensson em seu site, (Fonte: franksvensson.blogspot.com.br) foi comunicado a Paris pela academia de Roma que o comportamento de Garnier não era condizente com a época, os esboços de uma cidade do futuro foram destruídos e para continuar seu trabalho em Roma, dedicou-se à reconstrução de toda Tusculum, uma cidade da Antiguidade hoje conhecida como Frascati, localizada na antiga Itália (Lácio).

Retornando a Paris, em 1904, a reconstrução de Tusculum tornou-se objeto de exposição e foi aprovada como seu trabalho principal. Foi autorizado a expor também os esboços de sua cidade do futuro, como complemento a seu trabalho de Prix de Rome.

Em Lyon suas primeiras incumbências foram o seu famoso projeto de abatedouros, um grande hospital, um estádio municipal, uma exposição internacional. E em 1917 teve este trabalho publicado em dois volumes, com 164 pranchas, sob o título Une cité industriei/e, Étude pour La Construccion des Villes.

Garnier idealizou a cidade com uma população de 35.000 habitantes, não por achar que essa fosse uma quantidade ideal, mas por considerar que uma cidade menor não teria os problemas que gostaria de abordar arquitetonicamente, ao mesmo tempo em que uma cidade maior seria impossível de manusear da forma por ele desejada.

Em sua imaginada paisagem havia ainda uma microrregião, campos de lavoura capazes de nutrir a população urbana, um rio como via de transporte dos produtos industrializados. Um afluente capaz de produzir energia elétrica, luz e aquecimento para toda a cidade.

Pressupunha que a rede viária, o transporte, a água e o esgoto seriam de responsabilidade pública como também, a definição do uso do solo, o loteamento do mesmo, o abastecimento, a saúde e o lixo.

Garnier confronta sua nítida divisão da cidade em áreas de função especifica com a contínua ampliação da diversificada constituição urbana. Com estudos de insolação e ventilação para melhor conforto pessoal.

Uma cidade industrial tem como princípios diretores a análise e a separação das funções urbanas, a exaltação dos espaços verdes que desempenham o papel de elementos isoladores, a utilização sistemática dos materiais novos, em particular do concreto armado. (CHOAY, 1979, pág. 163). 
A cidade foi construída com base numa grelha de estradas perpendiculares e paralelas, imaginada em torno de uma via principal. Tem sua origem na praça da estação ferroviária, e as vias foram distribuídas no sentido leste-oeste, para seguir a melhor orientação solar. As ruas norte-sul teria largura de 20 metros e as leste-oeste de 13 a 19 metros. Todos os principais prédios públicos estariam concentrados no distrito central e seriam agrupados por funções: a. Serviços administrativos e locais de encontros; b. Museus; c. Esportes e lazer. Os prédios de serviços administrativos, locais de encontros e os museus estariam situados em parques e em uma rua principal. As escolas primárias seriam distribuídas ao longo do setor residencial. As partes vegetativas entre as casas funcionam de livre acesso aos pedestres. O tráfego de veículos é vinculado à via principal no sentido leste-oeste partindo da estação da estrada de ferro. No projeto só o simples, o prático e o verdadeiro são aceitos como belo.

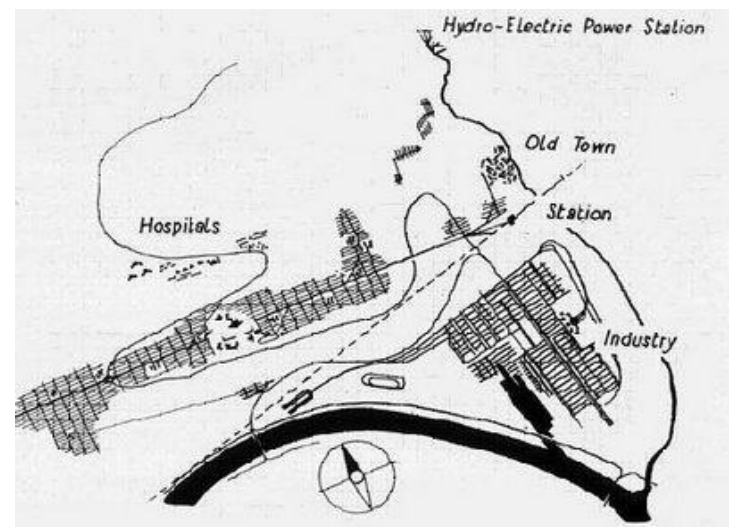

Figura 1. Esquema de zoneamento cidade industrial de Tony Garnier Fonte:http://franksvensson.blogspot.com.br/2013_02_01_archive.html

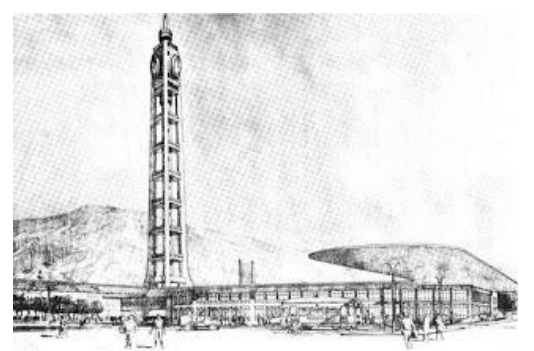

Figura 2. Estação Central da cidade

Fonte: http://tonygarnier.blogspot.com.br/2011/06/tony-garnier-e-seu-conceito-sobre.html

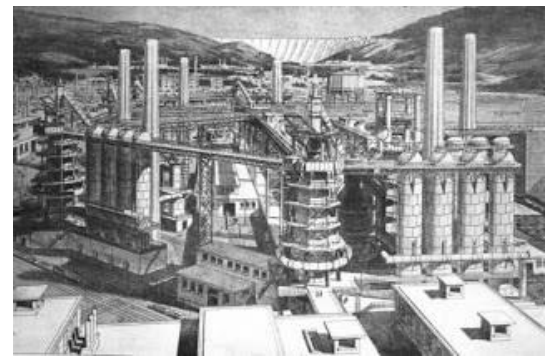

Figura 3. Zona Industrial

Fonte: http://tonygarnier.blogspot.com.br/2011/06/tony-garnier-e-seu-conceito-sobre.html 

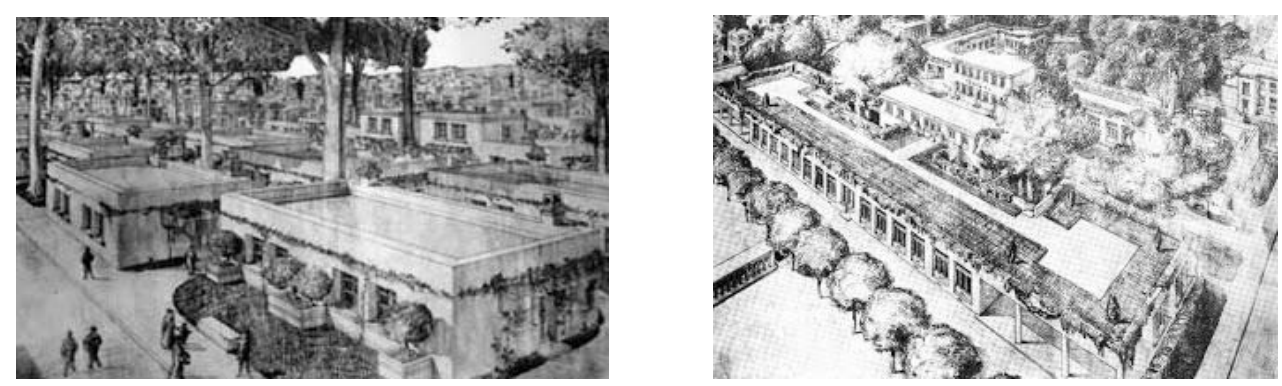

Figura 4. Zonas Residencial e profissional

Fonte: http://tonygarnier.blogspot.com.br/2011/06/tony-garnier-e-seu-conceito-sobre.html

\section{CONCLUSÃO}

Conclui-se que o arquiteto Tony Garnier foi relevante para a história da urbanística moderna após a revolução industrial, com suas soluções para uma cidade ideal e adequada devido aos problemas habitacionais e péssimas condições sanitárias naquele período.

Tony Garnier com sua proposta para uma cidade industrial separou distintos lugares em zoneamento onde facilitaria o meio de locomoção dos habitantes e além de tudo uma cidade organizada. Sua proposta foi concretizada na cidade de Lyon na França, cidade em que nasceu e viveu com seus pais, e lá fez inúmeras obras como a Halle Tony Garnier, lugar que hoje é conhecido como Monumento Histórico por todo o mundo e que realiza diversos eventos como concertos musicais e shows.

\section{REFERÊNCIAS}

ANDRÉA COSTA. O surgimento do urbanismo e as propostas de solução para as cidades. Disponível em: < docente.ifrn.edu.br/andreacosta/lazer-e-urbanismo/aula-05-a-08-propostas-urbanisticasdo-sec.-xix >. Acesso em: 9 agos. 2014.

BENEVOLO, Leonardo, 1923- A arquitetura no novo milênio / Leonardo Benevolo; tradução Letícia Martins de Andrade. - São Paulo: Estação Liberdade, 2007. 496 p. : il.

BENEVOLO, Leonardo,1981- As origens da urbanística moderna / Leonardo Benevolo; tradução Conceição Jardim e Eduardo L. Nogueira.

CHOAY, Françoise. O Urbanismo. Editora Perspectiva, São Paulo, 1979.

FIFIAPG. Tony Garnier e seu conceito sobre arquitetura, junho, 2011. Disponível em: <tonygarnier.blogspot.com.br/2011/06/tony-garnier-e-seu-conceito-sobre.html >. Acesso em: 9 agos. 2014.

FRANK SVENSSON. Tony Garnier e sua antevisão do século XX, fevereiro, 2013. Disponível em: < franksvensson.blogspot.com.br/ >. Acesso em: 9 agos. 2014. 
SILVANA CRISTINA. Cidade e Utopia, fevereiro, 2011. Disponível em: <portalarquitetonico.com.br/cidade-e-utopia-novos-modelos-sociais-e-espaciais/ >. Acesso em: 9 agos. 2014.

SYLVIANE LEPRUN. Maneiras de Instalações. Porto arte, Porto Alegre v.10, n.18, p.19-42, maio. 1999. Disponível em: <www.seer.ufrgs.br/PortoArte/article/viewFile/27771/16368 >. Acesso em: 9 agos. 2014 